\title{
Applying Ajzen's Theory of Planned Behaviour to the 'Keep Zambia Clean and Healthy' Programme
}

\author{
Bernard Chileshe, Charles M Namafe
}

\begin{abstract}
The theory of planned behaviour (TPB), proposed by Icek Ajzen in 1985, was applied to the study of the implementation of the 'Keep Zambia Clean and Healthy" campaign, a behaviour change programme aimed at keeping surroundings in Zambia clean, healthy and green in order to improve health standards of Zambians throughout the country. The determinants of pro-environmental behaviour postulated by the theory were studied in the light of the implementation of the programme. The survey randomly selected and interviewed 545 respondents, who were heads of household, in Lusaka and Mumbwa, using a closed-ended questionnaire. Following Schwartz (1992), respondents rated their responses on a 4-point or 5-point scale. Consistent with earlier research, the study found a gap between the knowledge and values held by the respondents on one hand and their behavioural action on the other. While the respondents professed good knowledge about the benefits of living in clean and sanitary environments, their behaviours did not show that they had engaged in environmentally friendly behaviour. The results, therefore, showed that giving people information alone may be too limited to bring about desired environmental behaviour.
\end{abstract}

Keywords: Environmental knowledge; values; attitudes; perceptions; pro-environmental behaviour.

\section{BACKGROUND AND CONTEXT}

Concerns for clean and sanitary environments have increasingly attracted national attention in Zambia (ECZ, 2001). These concerns are reflected differently within national policies and practices that express the growing advocacy for clean and healthy environments. In other words, the concept of clean and healthy environments has become an emergent but increasingly strong voice of all those militating against dirty environments in the country. It is argued here that dirty surroundings in the country have been a result of lack of pro-environmental behavior among many Zambians. This view is supported by Geller and Lehman (1986: 58) who have stated that "inappropriate solid waste management is primarily a behavioural problem. In other words, environmental pollution and degradation is the unfortunate outcome of undesirable human behaviour." In an effort to promote healthy living behaviour among Zambians, the government introduced the 'Keep Zambia Clean and Healthy' (KZCH) campaign on $22^{\text {nd }}$ June 2007 (Times of Zambia, $22^{\text {nd }}$ June 2007). Over the years, the government has crafted and tried to implement the programme. However, very little has been achieved in terms of achieving the objectives of the programme. Studies done by Banda (2013) in Mutendere Township in Lusaka, Chaampa (2014) in Kaunda Square in Lusaka, and Mwiinga (2014) in Choma district in Southern Province show that poor waste disposal contributed immensely to dirty and unsanitary surroundings in many Zambian townships. Because of such findings, it was important to investigate why many Zambians did not portray environmentally friendly behaviour. The theory of planned behaviour (TPB), which is a behaviour change theory, was utilized to achieve this. Results of this study were vital because they could be used for the development of intervention strategies that might promote pro-environmental behaviour among Zambians.

\section{THEORETICAL FraMEWORK}

A number of social-cognitive theories attempt to understand the factors behind human behaviour in general and waste management behaviour in particular. One of these theories is the theory of planned behaviour (TPB), proposed by Icek Ajzen in 1985. The theory is among the most cited theoretical frameworks for predicting a wide range of behaviors (Hall and Fong, 2007). Like its forerunner, the Theory of Reasoned Action (TRA) which was proposed by Martin Fishbein and Icek Ajzen in 1975, the TPB is grounded in various theories of behaviour and attitude, such as learning theory (Sheppard, Hartwick and Warshaw, 1988). It contends that people, being rational beings, estimate certain factors before deciding to engage or not to engage in a behaviour. Chakema and Rhonda (2009) called this 
intent factor. This is to say that if people evaluate the suggested behaviour as positive (attitude), and if they think that their significant others want them to perform the behaviour (subjective norm), this results in a higher intention (motivation) and they are more likely to do so (Ajzen, 1991; Francis et al., 2004). However, because of circumstantial limitations, behavioural intention does not always lead to actual behaviour. Therefore, 'perceived behavioural control' or self-efficacy is added to cover nonvolitional behaviours for predicting behavioural intention and actual behaviour. Consequently, to predict whether a person intends to do something or not, we need to know three predictors or determinants: behavioural beliefs (attitude), normative beliefs (subjective norm), and control beliefs (perceived behaviour control) (Francis et al., 2004: 7). This is shown in Figure 1.

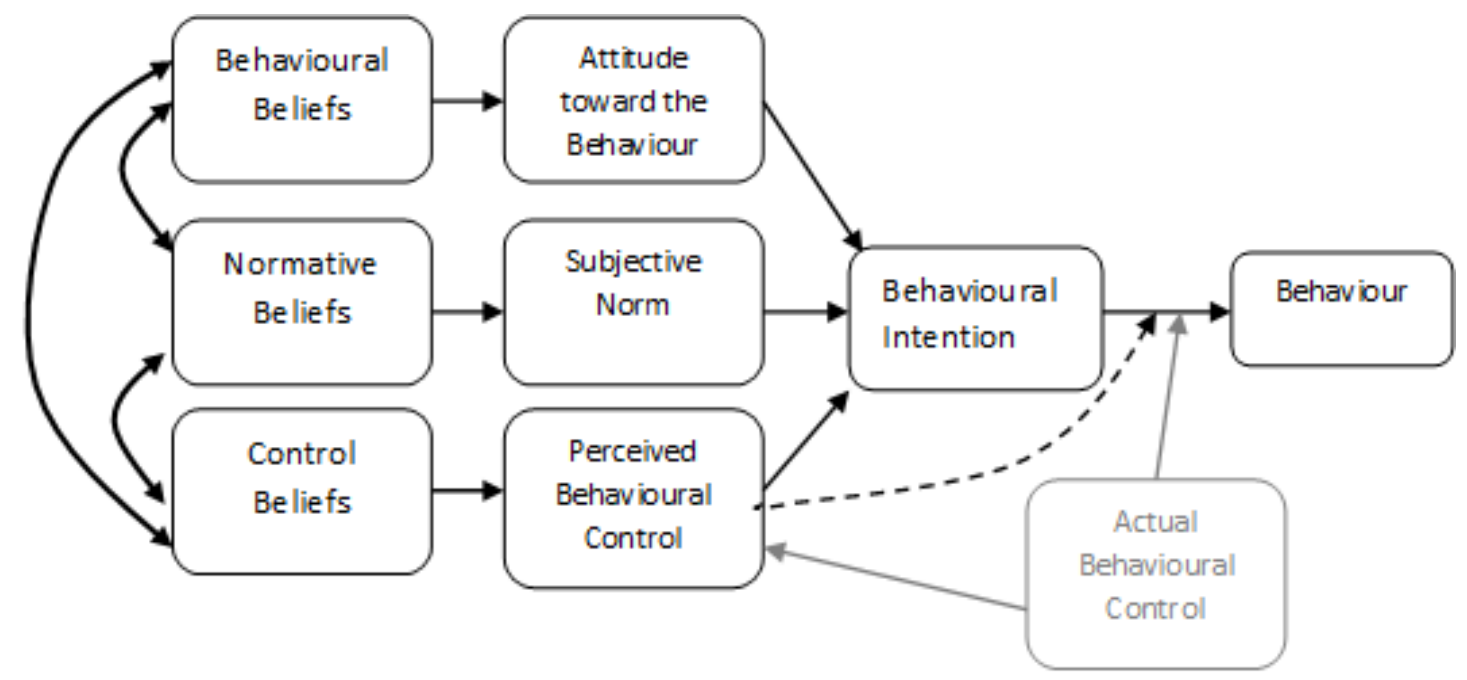

Figure1. The Theory of Planned Behaviour

Source: Ajzen (1991)

This study looked at how both motivation (or volitional control) and circumstantial limitations could be applied to the implémentation of the 'Keep Zambia Clean and Healthy' programme.

\section{AIM OF THE STUDY}

This study aimed at assessing public environmental behaviour using the constructs of the theory of planned behaviour in relation to the Keep Zambia Clean and Healthy programme. The constructs were behavioural beliefs (attitude), normative beliefs (subjective norm), and control beliefs (perceived behaviour control). Can these constructs be significant predictors of environmental behaviour with regard to the $\mathrm{KZCH}$ programme?

\section{LiteratURE REVIEW}

Past research has shown that the TPB has utility in the study of knowledge, values, beliefs and attitudes held by a group of people (Chakema \& Rhonda, 2009). According to Armitage and Christian (2003 cited in NICE, 2007), there is a large volume of research indicating that the theory has utility in predicting environmental behaviours. Examples of studies which utilized the TPB include Knabe (2012) who used the theory to study online course adoption in public relations education and Morris and Venkatesh (2000) who applied the theory to study workers' decisions about technology usage and their attitudes toward adoption of technology. These previous studies reveal successful applications of the theory. They also reinforce the utility of the theory for research involving various types of behaviour. The significance of the current study is that it expands upon the growing body of literature specific to behaviour change, especially related to the environment.

Kollmuss and Agyeman (2002) have asserted that people's decisions regarding the selection of behaviours towards the environment are guided by personal knowledge, values, beliefs and attitudes. Scholars, such as Dunlap, Grieneeks, and Rokeach (1983) and Stern and Dietz (1994), have shown that knowledge, values and attitudes are related to pro-environmental behaviour and to people's willingness to take action to protect the environment. However, like many environmental behaviours, participation in environmental programmes such as the $\mathrm{KZCH}$ programme is not entirely under volitional control (that is, behavioural beliefs) but also under non-volitional controls such as subject norms (that is, the views of significant others) and perceived behaviour control (also called self- 
efficacy, self-concept or control beliefs) (Fila \& Smith, 2008). In addition, scholars such as Mullan and Wong (2009) have added a component of past behaviour to the TPB and found that past behaviour had a robust effect on future behaviour. However, Azjen and Fishbein (2005) have argued that past behaviour does not have the same status as other predictors of behaviour. They argue that frequency of past behaviour cannot explain performance of later action. This study examines these constructs in the light of the implementation of the KZCH programme.

\section{Methodology}

The study was developed following procedures defined by Schwartz (1992). A self-administered questionnaire was distributed to five hundred and forty-five $(\mathrm{n}=545)$ randomly selected households in Mumbwa (245) and Lusaka (300). The questionnaire used closed-ended questions to elicit information on the four constructs of the TPB. The respondents rated their responses either against a 4-point or 5-point Likert scale, as proposed by Schwartz (1992). The data collected were then analysed using counts (frequencies) and percentages and were displayed in graphs.

\subsection{Findings}

The results of the study have been presented according to the main predictors of behaviour as postulated by the TPB. Concerning behavioural beliefs, the results (Figure 2a) indicate that over half of the respondents (53\%) stated that they knew something about the $\mathrm{KZCH}$ programme. Only $16 \%$ stated that they did not know anything about the programme. The majority of respondents $(90 \%)$ indicated that the issue of keeping the environment clean was very important to them (Figure 2b). A descriptive statistical analysis of the data elicited on this question showed a median of 2 (important) and a mode of 1 (very important). This shows that most the respondents felt that the issue of keeping the environment clean was very important.
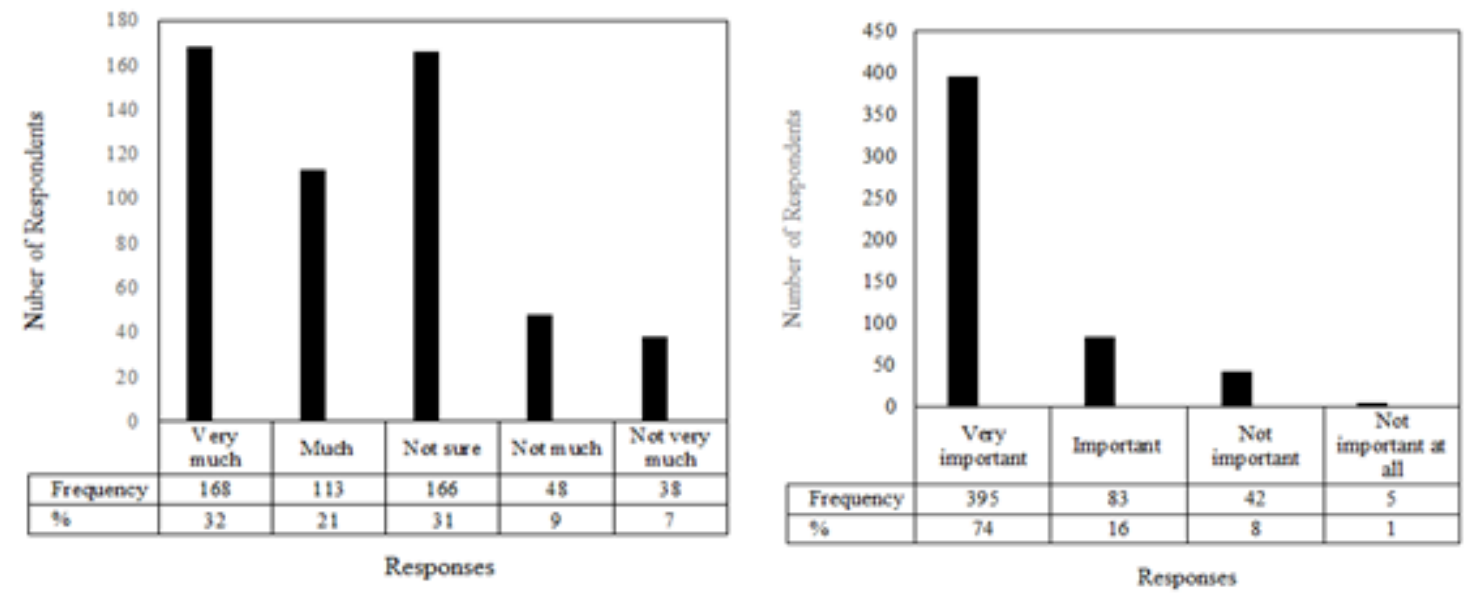

Figure2. (A) Knowledge About The KZCH Programme and (B) Perceptions about Importance of Keeping the Environment Clean and Healthy

Subjective norm was measured by asking the respondents how significant others (friends, family members and colleagues) influenced their behaviour. The results in Figure 3 (a) show that $36 \%$ ( $\mathrm{n}=$ $193)$ of the respondents affirmed that significant others were very influential while $25 \%(n=137)$ stated that they were influential, $21 \%(\mathrm{n}=113)$ stated little influence and $18 \%(\mathrm{n}=98)$ no influence at all. Altogether, $82 \%$ of the respondents indicated that the significant others were influential in some way. Both the median and modal scores were 1.00 (very influential) showing that the most prevalent response was 'very influential'.

The respondents were also asked about what the views of the significant others would be if they found out that the respondents were taking part in the $\mathrm{KZCH}$ programme. The results (Figure 3b)revealed that $46 \%(\mathrm{n}=250)$ of the respondents stated that their significant others would view their participation in the KZCH programme very favourable, $23 \%(\mathrm{n}=126)$ stated favourable, $20 \%(\mathrm{n}=108)$ were not sure, $6 \%(\mathrm{n}=32)$ unfavourable, and $5 \%(\mathrm{n}=25)$ very unfavourable. Altogether, $69 \%$ of the respondents thought that their significant others' views would be favourable to very favourable. The median score was 2 (favourable) while the modal score was 1 (very favourable). 

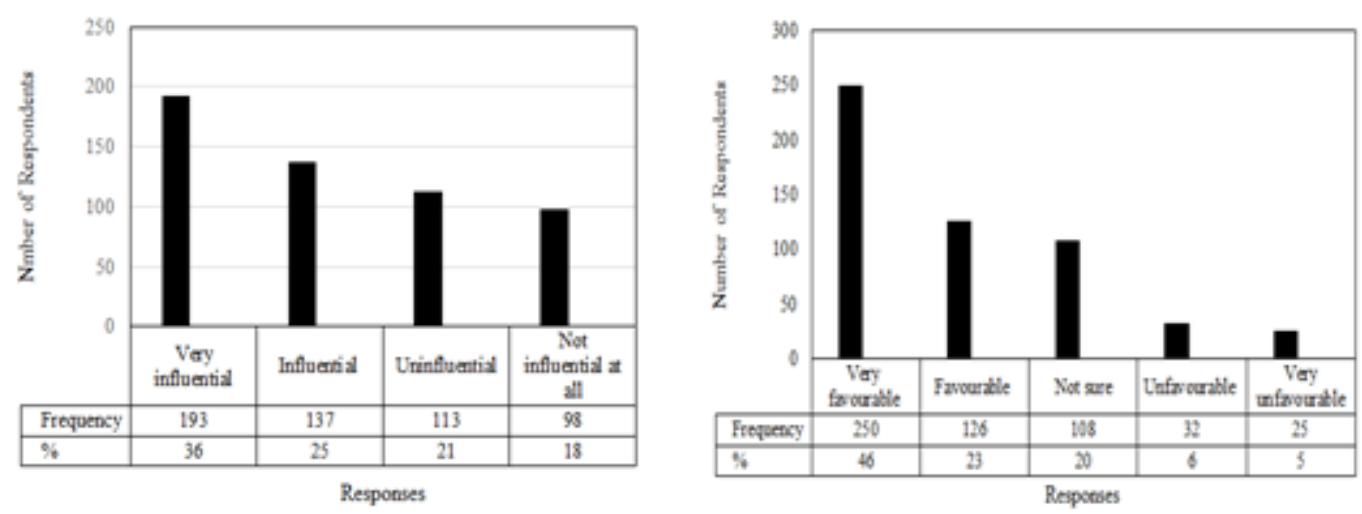

Figure3. Subjective norm (a) Influence by people known to the respondents (b) Perceptions of the views of significant others

For perceived behaviour control or how easy the respondents found it to participate in the KZCH programme, the results (Figure 4) show that $46 \%(\mathrm{n}=251)$ of the respondents said that they found it very easy, $30 \%(n=165)$ easy, $17 \%(n=93)$ not easy and $11 \%(n=62)$ not easy at all. All in all, 76 $\%$ of the respondents indicated that they found it easy to participate in the KZCH programme while $28 \%$ said they did not find it easy. The median response was 2.00 (easy) and the modal response was 1 (very easy), meaning the most prevalent answer was 'very easy'.

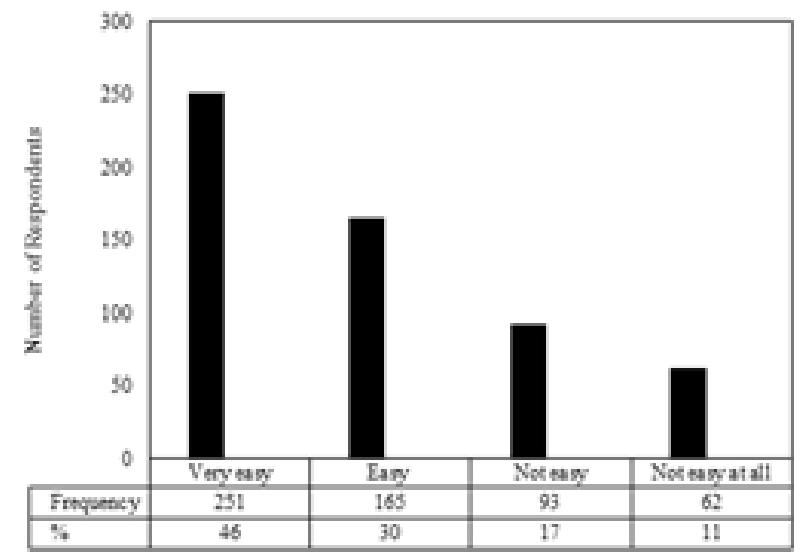

Figure4. Perceived behaviour control

To ascertain past behaviour, respondents were asked to state (using 'yes' or 'no') whether or not they had participated in the programme in the past. The results (Table 1) show that slightly less than half the respondents in the survey $(49.7 \%$ or $n=267)$ indicated that they had taken part in the programme in the past while the rest $(50.3 \%$ or $\mathrm{n}=270)$ stated that they had not taken part. The difference between respondents who said they were currently taking part in the $\mathrm{KZCH}$ programme and those who said they had participated in the programme before was $14.3 \%$. Of these, only $0.94 \%$ said they would continue taking part in the programme in future.

Table1. Respondents Taking Part in the KZCH Programme in the Past

\begin{tabular}{|c|c|c|}
\hline Response & Frequency & $\%$ \\
\hline Yes & 267 & 49.7 \\
\hline No & 270 & 50.3 \\
\hline Total & $\mathbf{5 3 7}$ & $\mathbf{1 0 0 . 0}$ \\
\hline
\end{tabular}

Results for behavioural intention for those not participating in the programme ( 269 or $49.36 \%$ of the sample) (Figure 5a) show that $62.6 \%(\mathrm{n}=169)$ of the respondents indicated that they would definitely participate in the programme in future, $18.3 \%(\mathrm{n}=49)$ said they would participate, $8.3 \%(\mathrm{n}=22)$ said they would not and $10.8 \%(\mathrm{n}=29)$ said they would not definitely participate in the programme. Altogether, $80 \%$ of the respondents $(\mathrm{n}=218)$ who were not participating in the $\mathrm{KZCH}$ programme indicated that they would somehow participate in the programme in future. Both the median and modal scores were $=1.00$ (definitely will), an indication of willingness to participate. 
For the 276 respondents (or $50.6 \%$ of the sample) who were already participating in the programme, results for behavioural intention (Figure $5 \mathrm{~b})$ show that $64.1 \%(\mathrm{n}=171)$ indicated that they would definitely continue participating, $22.2 \%(\mathrm{n}=59)$ said they would continue, $7.4 \%(\mathrm{n}=20)$ said they would not continue and $6.3 \%(\mathrm{n}=17)$ said they would definitely not continue. All in all, eighty-six percent of the respondents who were already participating indicated that they, one way or another, intended to continue participating into the future.
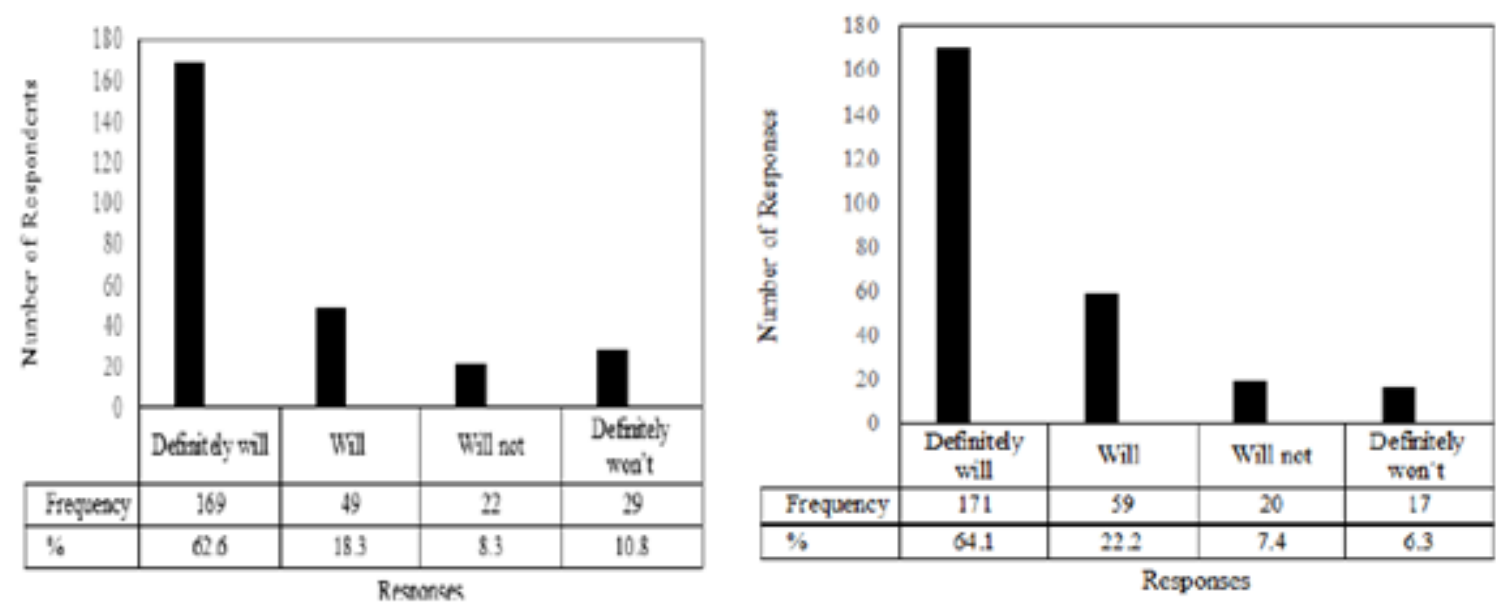

Figure5. Behavioural intention (a) by those not participating and (b) by those already participating in the programme

\section{Source: Field data}

Results for control belief (Figure 6a) show how the respondents perceived themselves in relation to participating in the KZCH programme. Fourteen percent $(14 \%$ or $n=73)$ of them strongly agreed, $9 \%(\mathrm{n}=48)$ agreed, $9 \%(\mathrm{n}=50)$ were not sure $11 \%(\mathrm{n}=59)$ disagreed and $57 \%(\mathrm{n}=310)$ disagreed strongly that they were not the type of people who would participated in the programme. Altogether, $68 \%$ of the respondents disagreed with the assertion that they were not the type of people who would take part in the $\mathrm{KZCH}$ programme.
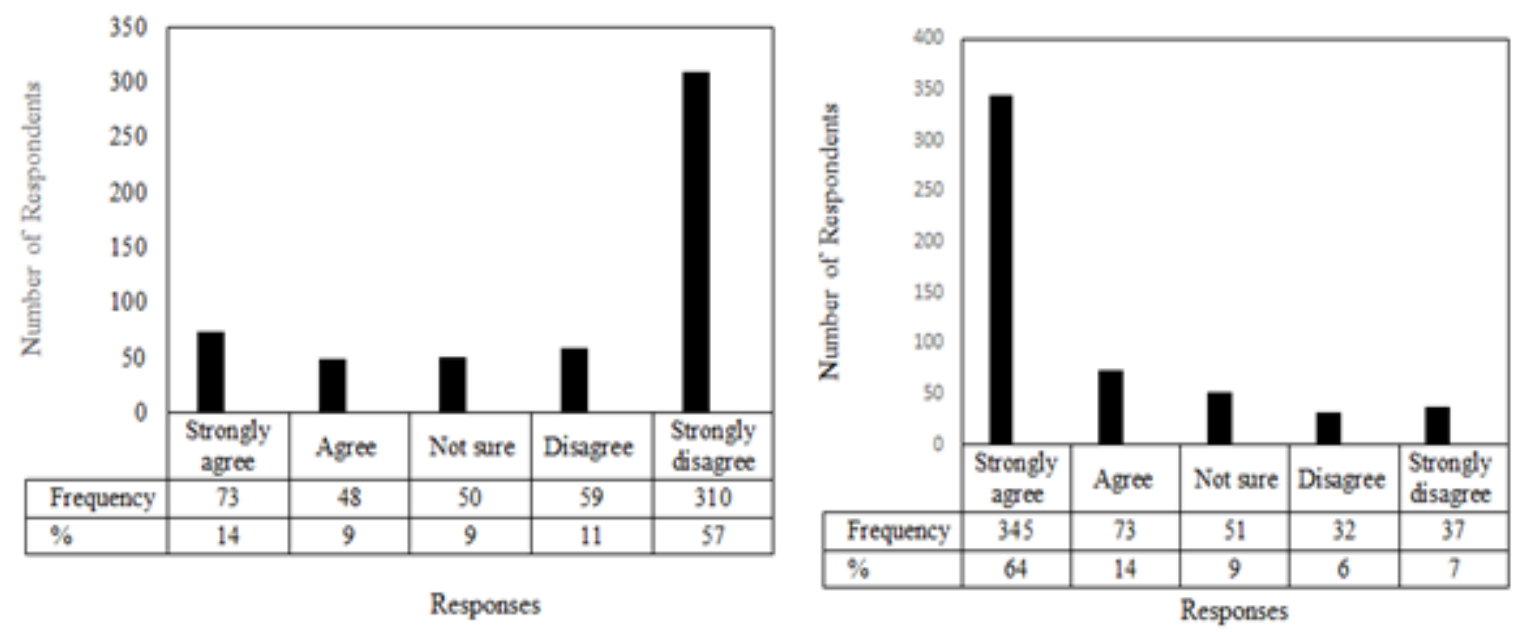

Figure6. Control belief or self-concept by respondents (a) as not the type of people who could take part in the $\mathrm{KZCH}$ programme and (b) as type of people who would take part in the KZCH programme

\section{Source: Field data}

The results in Figure $6(\mathrm{~b})$ show that $64 \%(\mathrm{n}=345)$ of the respondents strongly agreed, $14 \%(\mathrm{n}=73)$ agreed, 9\% ( $\mathrm{n}=51)$ were not sure, 6\% $(\mathrm{n}=32)$ disagreed and $7 \%(\mathrm{n}=37)$ disagreed that they perceived themselves as people who would participate in the $\mathrm{KZCH}$ programme. Altogether, $78 \%$ of the respondents agreed with the assertion that that they were the type of person who would take part in the $\mathrm{KZCH}$ programme.

\subsection{Pro-Environmental Values}

Results for the pro-environmental values of the respondents are shown in Figure 7. 

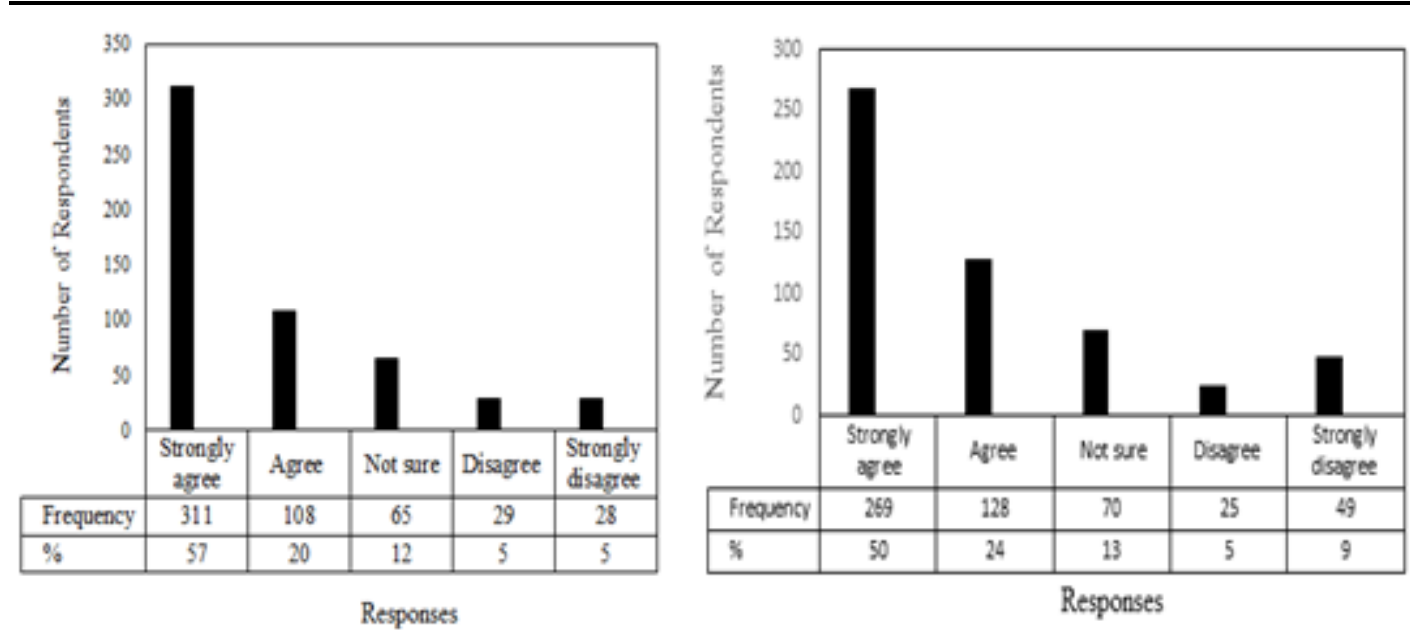

Figure7. (a) Self-perception as environmentally-friendly people (b) Concern with environmental issues

Source: Field data

For self-perception (Figure 7a), the results show that $50 \%(n=269)$ of the respondents agreed strongly that they held pro-environmental values, $24 \%(\mathrm{n}=128)$ agreed, $13 \%(\mathrm{n}=70)$ were not sure, $5 \%(\mathrm{n}=25)$ disagreed while $9 \%(\mathrm{n}=49)$ strongly disagreed. In all, $74 \%$ of the respondents indicated that they thought of themselves as environmentally-friendly consumers. For concern with environmental issues (Figure $7 \mathrm{~b})$, resultsshow that $57 \%$ (or $\mathrm{n}=311)$ strongly agreed, $20 \%(\mathrm{n}=108)$ agreed, $12 \%(\mathrm{n}=65)$ were not sure, $5 \%(\mathrm{n}=29)$ disagreed and $5 \%(\mathrm{n}=28)$ strongly disagreed that they thought of themselves as people who were very concerned with environmental issues. In total, $77 \%$ of the respondents thought of themselves as people who were very concerned with environmental issues. Both the median and mode were $=1.00$ (strongly agree). Figure 8 (a) shows that only $19 \%(\mathrm{n}=103)$ of the respondents strongly agreed that they would be embarrassed to be seen to have an environmentally friendly lifestyle, $13 \%(\mathrm{n}=70)$ agreed, $9 \%(\mathrm{n}=47)$ were not sure, $6 \%(\mathrm{n}$ $=34)$ disagreed while $53 \%(\mathrm{n}=286)$ strongly disagreed. All in all, 59\% of the respondents felt that they would not be embarrassed to be seen to have an environmentally friendly lifestyle. Both median and modal scores were 5.00 (strongly disagree).
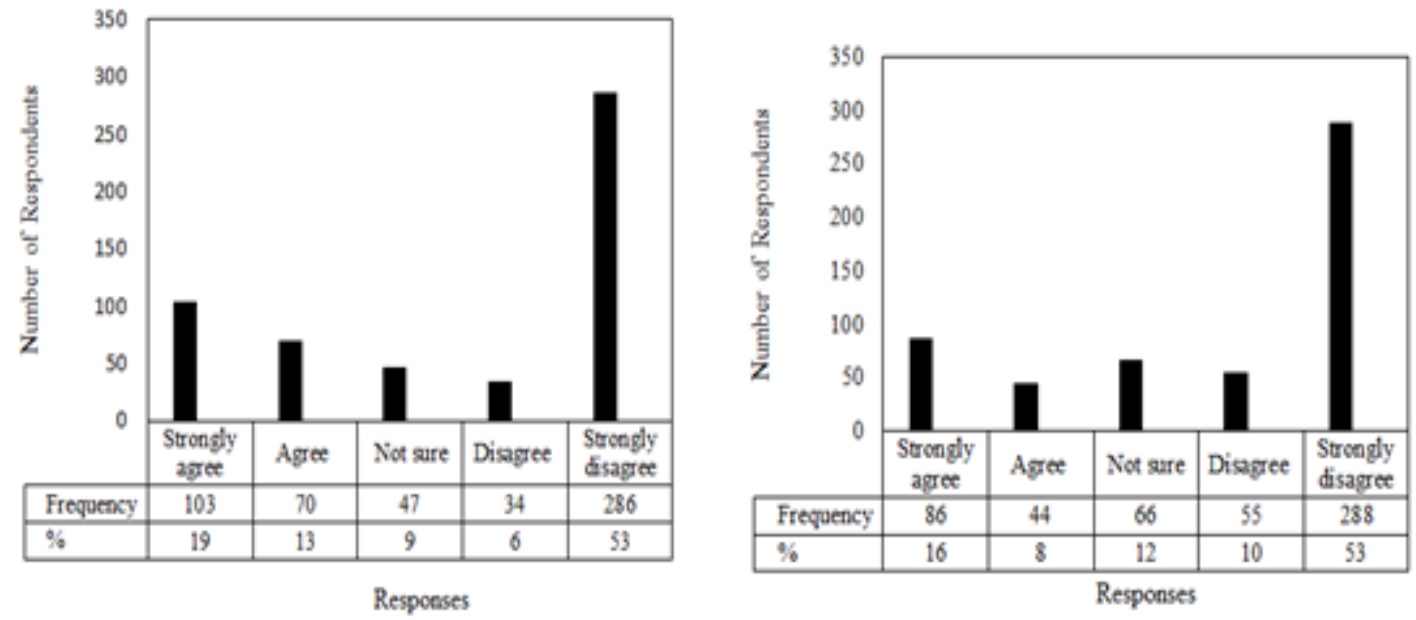

Figure8. (a)Feeling embarrassed to be seen to have an environmentally friendly lifestyle and (b) Family, colleagues or friends not to think of respondent as someone who was concerned about environmental issues.

\section{Source: Field data}

The results (Figure 8 b) also show that $16 \%(n=86)$ of the respondents strongly agreed, $8 \%(n=44)$ agreed, $12 \%(\mathrm{n}=66)$ were not sure, $10 \%(\mathrm{n}=55)$ disagreed and $53 \%(\mathrm{n}=288)$ disagreed strongly that they would not want their significant others to think of them as people who were concerned about environmental issues shows that sixteen percent. In total, $63 \%$ of the respondents indicated that they would want their family or friends to think of them as someone who is concerned about environmental issues. Both the median and mode $=5.00$ (strongly disagree). 


\section{DISCUSSION}

Would the TPB be applied to the implementation of the $\mathrm{KZCH}$ programme? Concerning behavioural beliefs, this study has established that the majority of the respondents $(90 \%)$ were aware of the importance of keeping the environment clean and healthy. These findings are similar to those of Banda (2013) whose study among the residents of Mutendere Township in Lusaka established that awareness of the importance of a clean environment was as high as $94 \%$. This finding also agrees with Harvey and Mukosha's (2008) assertion that "most of the community members are aware of the awareness campaign and understand its benefits ..." Nevertheless, this seemingly good awareness level was not accompanied by good responsive behaviour towards the wellbeing of the environment. Like in the case of pupils studied by Molapo et al. (2014) in Lesotho, there was no relationship between knowing and the action taken. This contradiction negated the benefits of the awareness of the need to live in clean and sanitary environments. Several reasons have already been advanced by scholars such as Mukosha and Harvey (2008), Banda (2013), Molapo et al. (2014) and Mwiinga (2014). Some of the reasons are that community members do not always act appropriately because they may not be convinced of the consequences of the dirty and unsanitary environment, that is, they may not be aware of the perceived risks of a dirty environment Mukosha \& Harvey (2008). Molapo et al. (2014) suggest a type of education which makes learners action competent through acquisition of new values, motivations and habits. Some scholars have also argued that the KZCH programme has failed to produce the expected results because of failure by those implementing it to involve the community from the initial stages of planning to implementation. Mukosha and Harvey (2008) assert that the $\mathrm{KZCH}$ programme is a good motive which requires active dissemination of information about it and its benefits. It also requires increased involvement of stakeholders (the principle of cooperation) at every stage of programme planning and implementation.

The results also show that the subjective norm or normative belief is a strong predictor of behaviour in the implementation of the $\mathrm{KZCH}$ programme. Eighty-one percent ( $81 \%)$ of the respondents indicated that they would seek the approval of their significant others before engaging in the programme. This finding is consistent with the first principle of behavioural economics which states that much of our behaviour is strongly influenced by other people's behaviour (Aronson, Wilson and Akert, 2005). When people are required to make a conscious decision on how to behave, their sense of social identity is important - they think: how would other people from 'my group' behave in this situation? (NEF, 2005). It is, therefore, imperative for the KZCH programme to identify the existing social capital (that is, where there are strong networks between people and a high level of mutual trust) in order to influence people's behaviour. Social networks can be used to enhance the implementation of the $\mathrm{KZCH}$ programme.

As for perceived behaviour control, the findings suggest that the majority of respondents $(76 \%)$ felt that they found it easy to participate in the $\mathrm{KZCH}$ programme. The implication for the programme is that most of the members of the general public did not have a problem taking part in the programme because they felt that it was positive behaviour and so there was motivation to participate in the programme which they considered worthwhile. People tend to behave in a way that supports the impression of a positive and consistent self-image (Dolan et al., n.d.). According to Sheppard, Hartwick and Warshaw (1988), if people evaluate the suggested behaviour as positive (attitude), they may have higher motivation and they are more likely to undertake the behaviour. In this case, then, appropriate behaviour may be spurred by such environmental behaviour tools such as commitment, feedback, goal-setting, incentives and prompts (McKenzie-Mohr and Schultz, 2012).

Concerning behavioural intention, the results have shown that most respondents indicated that they would participate in the $\mathrm{KZCH}$ programme in future. The question that arises is: is this desire to participate in the programme in future affected by the respondents' past behaviour or not? Although only $49.7 \%$ of the respondents had indicated that they had taken part in the $\mathrm{KZCH}$ programme in the past, $80 \%$ of them stated that they would take part in the programme in future. This shows a discrepancy between past behaviour and behavioural intention. The implication for the KZCH programme, therefore, is that many respondents who did not taken part in the programme before were willing to take part in future. However, it is also likely that respondents who had taken part in the programme in the past may not continue taking part in future. In this regard, it can be concluded that the respondents may not have been affected by past behaviour, that is, their future behaviour may not entirely depend on past behaviour (Franklin, 2013). The truth, therefore, is that some past behaviour 
does recur and, therefore, there is a possibility that a respondent who took part in the $\mathrm{KZCH}$ programme before would still take part in the future. Among the conditions for a behaviour to recur is that it should be a high frequency, habitual behaviour, not an infrequent one. This gives the cue that the implementation of the KZCH programme should not be episodic or sporadic, but an ongoing activity if past behaviour is going to have an effect on future behaviour.

The results for behavioural intention indicate that whether people were taking part in the programme at the time of the study or not, their behavioural intention was to take part in future. This is a good indicator for the $\mathrm{KZCH}$ programme. However, there is need for people in authority to sustain motivation for those already taking part in the programme and to put in place initiatives that would bring on board those who were not. It is necessary to indicate at this point that when people state their behavioural intention they should elaborate it, for example, in terms of how, when and where the action will be performed. In this study, the respondents only expressed goal intention and not implementation intention. Without specifying the implementation intention in planning, it is likely that the behaviour may not be performed (Gollwitzer and Brandstatter, 1997). Alternatively, the respondents could have stated the behavioural intention in terms of specific situations, such as, when I go to a shopping outlet, I will not accept a plastic shopping bags. Gollwitzer and Brandstatter state that this type of behavioural intention is grounded in self-regulation theory while the other types are grounded in motivation theory.

\section{CONCLUSION}

The TPB has shown utility in previous studies and is one of the most cited theoretical frameworks for predicting a wide range of behaviours. The results of this study show that the theory can also be applied to the implementation of the KZCH programme and can be useful for explaining the failure of success of the programme. The implementers of the programme, therefore, need to familiarise themselves with the constructs of the theory in order to benefit from its stipulations.

\section{REFERENCES}

[1] Ajzen, I. (1991). The theory of planned behaviour. Organizational Behaviour and Human Decision Processes, 50, 179-211.

[2] Ajzen, I. \& Fishbein, M. (2005). The Influence of Attitudes on Behavior. In D. Albarracín, B. T. Johnson, and M. P. Zanna (Eds.), The Handbook of Attitudes (pp. 173-221). Mahwah, NJ: Erlbaum.

[3] Ajzen, I. \& Fishbbein, M. (1980). Understanding attitudes and predicting social behaviour. Englewood Cliffs, NJ: Prentice Hall.

[4] Aronson, E., Wilson, T.D., \& Akert, A.M. (2005). Social psychology (5 $5^{\text {th }}$ Edition). Upper Saddle River, NJ: Prentice Hall.

[5] Banda, E. (2013). Factors leading to poor outcomes of the Keep Zambia Clean Awareness campaign: the case of Mtendere residential area of Lusaka. Unpublished dissertation submitted to the University of Zambia in partial fulfilment of the research requirements for the award of the degree of Master of Education in Adult Education, Lusaka.

[6] Chakema, C.C. \& Rhonda, K.L-M. (2009). Examining the Theory of Planned Behaviour Applied to Condom Use: The Effect-Indicator vs. Causal-Indicator Models. The Journal of Primary Prevention, 30 (6): 659-676.

[7] Chaampa, V. (2014). An assessment of environmental awareness on sustainable solid waste management in Lusaka: A case of Kaunda Square Township. Unpublished dissertation submitted to the University of Zambia in partial fulfilment of the requirements for the award of the degree of Master of Education (Sociology of Education), Lusaka: University of Zambia.

[8] Dolan, P., Hallsworth, M., Halpern, D., King, D. \& Vlaev, I. (n.d.). Mindspace: Influencing behaviour through public policy - The practical guide. Cabinet Office, Institute for Government, UK.

[9] Dunlap, R. E., Grieneeks, J. K., \& Rokeach, M. (1983). Human values and pro-environmental behaviour. In Conn, W.D. (ed.), Energy and Material Resources: Attitudes, Values, and Public Policy. Boulder, CO: Westview. 
[10] ECZ (2001). State of the Environment in Zambia 2000. Lusaka: Examinations Council of Zambia.

[11] Fila, S.A. \& Smith, C. (2006). Applying the Theory of Planned Behavior to healthy eating behaviors in urban Native American youth. International Journal of Behavioral Nutrition and Physical Activity 3 (11). DOI: 10.1186/1479-5868-3-11.

[12] Francis, J.J., Eccles, M.P., Johnston, M.,Walker, A., Grimshaw, J., Foy, R., Kaner, E.F.S., Smith, L., \&Bonetti, D.(2004). Constructing questionnaires based on the Theory of Planned Behaviour: A manual for health services researchers, Centre for Health Services Research University of Newcastle Centre for Health Services Research, University of Newcastle.

[13] Franklin, K. (2013). The best predictors of future behaviour is... past behaviour: Does the popular maxim hold water?

[14] Geller, E.S. and Lehman, G.R. (1986). Motivating desirable waste management behaviour: Application of behaviour analysis. Journal of Resource Management and Technology, 15 (2 \& 3), $58-68$.

[15] Gollwitzer, P. M. \& Brandstatter, V. (1997). Implementation intentions and effective goal pursuit. Journal of Personality and Social Psychology 73 (1), 186-199.

[16] Hall, P A. \& Fong, G. T. (2007). Temporal self-regulation theory: A model for individual health behaviour. Health Psychology Review 1 (1), 6-52.

[17] Harvey, P.A. \& Mukosha, L. (2008). Community-led total sanitation: Lessons from Zambia, UNICEF.

[18] Knabe, A. (2012). Applying Ajzen's Theory of Planned Behavior to a Study of Online Course Adoption in Public Relations Education. Dissertations (2009 -). Paper 186. Available from: http://epublications.marquette.edu/dissertations_mu/186. [Retrieved $18^{\text {th }}$ April, 2016].

[19] Kollmuss, A. \& Agyeman, J. (2002). Mind the gap: Why do people act environmentally and what are the barriers to pro-environmental behaviour? Environmental Education Research 8, 239-260.

[20] Molapo, L., Stears, M. \& Dempster, E. (2014). Does formal environmental knowledge inform the everyday practices of senior secondary biology learners in Lesotho? Southern African Journal of Environmental Education 30, 118-129.

[21] Mullan, B. A., \&Wong, C. L. (2009). Hygienic food handling behaviours. An application of the Theory of Planned Behaviour. Appetite, 52, 757-761.

[22] Morris, M.G. \& Venkatesh, V. (2000). Age differences in technology adoption decisions: Implications for a changing work force. Personnel psychology, 53(2):375 - 403.

[23] Mwiinga, F. (2014). Perceptions of solid waste management and the role of Environmental Education among selected residents of Choma Township of southern Zambia. Unpublished dissertation submitted to the University of Zambia in partial fulfillment of the requirements for the award of the degree of Master of Education (Environmental Education),Lusaka: University of Zambia.

[24] NEF (2005). Behavioural economics: Seven principles for policy-makers. The New Economics Foundation.

[25] NICE (2007). A review of the use of the Health Belief Model (HBM), the Theory of Reasoned Action (TRA), the Theory of Planned Behaviour (TPB) and the Trans-Theoretical Model (TTM) to study and predict health related behaviour change. The National Institute for Health and Clinical Excellence.

[26] Schwartz, S. H. (1992). Universals in the content and structure of values: Theory and empirical tests in 20 countries. In M. Zanna (Ed.), Advances in experimental social psychology 25, 1-65. New York: Academic Press.

[27] Sheppard, B.H.; Hartwick, J. \& Warshaw, P.R. (1988). The theory of reasoned action: A meta analysis of past research with recommendations for modifications and future research. Journal of Consumer Research 15, 325-343.

[28] Stern, P.C. \& Dietz, T. (1994).The Value Basis of Environmental Concern. Journal of Social Issues, 50 (3), 1994, 65-84.

[29] Times of Zambia (22 ${ }^{\text {nd }}$ June 2007). Mwanawasa to Launch Keep Zambia Clean Campaign. Available from: http://allafrica.com/stories/200706220922.html [Retrieved $16^{\text {th }}$ October, 2015]. 


\section{AUTHORS' BIOGRAPHY}

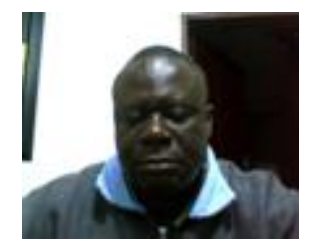

Bernard Chileshe, is a lecturer and $\mathrm{PhD}$ student of environmental education at the University of Zambia. His main research interest is in waste management behaviour. His current research projects focus on environmentally significant behaviour, human behaviour patterns in relation to environmental quality, quality of life, and sustainable development and indigenous knowledge systems in waste management.

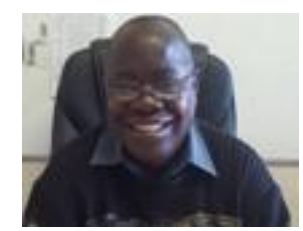

Charles M Namafe, Ph.D. is professor of environmental education at the University of Zambia. He has spearheaded the mainstreaming of environmental education in university curricula in Zambia and has extensively studied Zambian cultures and traditional ceremonies. 